\title{
The Nairobi Climate Change Summit (COP 12 - MOP 2): Taking a Deep Breath before Negotiating Post-2012 Targets?
}

\begin{abstract}
Wolfgang Sterk, Hermann E. Ott, Rie Watanabe and Bettina Wittneben*
Coming at the end of a year where public awareness of climate change had reached unprecedented heights, there was much hope by the general public that the United Nations climate change conference in Nairobi would be characterised by a renewed sense of urgency and seriousness. However, although a sense of urgency was present in many delegates individually, the conference proceeded with its usual diplomatic ritual at an almost surrealistic slow pace, apparently unaffected by time pressure. While it did see some progress on important issues for developing countries such as the Adaptation Fund, the Nairobi Work Programme on Impacts, Vulnerability, and Adaptation to Climate Change, and the Clean Development Mechanism (CDM), on questions regarding the future of the regime it proved to be at best a confidence-building session that served to hear further views. More serious work on the future of the regime can - and musttherefore be expected of the next Conferences of the Parties.
\end{abstract}

\section{Introduction}

The year 2006 may with hindsight be remembered as the watershed in climate policy, the year when the knowledge of the grim realities of climate change eventually trickled down from the elusive towers of the natural sciences into the societal and political spheres. This was partially due to the publication of the proceedings of the 'Exeter Conference', which transferred the notions of 'non-linear developments' and 'tipping points' of the Earth's ecosystems into popular knowledge. ${ }^{1}$ Since

\footnotetext{
* Wolfgang Sterk, Hermann E. Ott and Rie Watanabe all work with the Wuppertal Institute for Climate, Environment and Energy. Bettina Wittneben is Assistant Professor at the Rotterdam School of Management, Erasmus University Rotterdam.

1 See Schellnhuber et al (eds.), Avoiding Dangerous Climate Change, Cambridge 2006

2 www.hm-treasury.gov.uk/Independent_Reviews/ stern_review_economics_climate_change/sternreview_index.cfm.

3 For some critical assessments, however, see www.postnormaltimes.net/blog/and http://risingtidenorthamerica.org/sternreport.html.

4 For the sake of brevity and to minimise complexity the abbreviation MOP is used instead of COP/MOP for 'the Conference of the Parties (to the Convention) serving as the meeting of the Parties (to the Protocol)'.
}

the year 2006 it is thus widely known that large, vulnerable and vital ecosystems such as the arctic ice sheets or the tropical rainforests of the Amazon and Congo may be at risk of sudden collapse. The watershed was exacerbated by the publication of former World Bank economist Sir Nicholas Stern's 'Review on the Economics of Climate Change', which had been commissioned by the British government. $^{2}$ This comprehensive economic assessment of climate change put the costs of avoidance and mitigation much lower than the potential catastrophic losses of unmitigated warming. ${ }^{3}$

The expectations by the global public were thus running high for the United Nations climate change conference in Nairobi, Kenya. The twelfth Conference of the Parties to the Framework Convention on Climate Change (FCCC) (COP 12) and the second Meeting of the Parties to the Kyoto Protocol (MOP 2) ${ }^{4}$ took place from 6 to 17 November 2006 and there was much hope by the general public that the summit would be characterised by a renewed sense of urgency and seriousness. Nothing could have been further from what happened, however. Although a sense of urgency was present in many delegates individually, the conference proceeded with its usual diplo- 
matic ritual at an almost surrealistic slow pace, apparently unaffected by time pressure.

Nevertheless, the location of the conference in Nairobi, Kenya, certainly moved Africa into the spotlight of the climate policy process. The continent emits relatively few anthropogenic greenhouse gases but will be severely hit by the impacts of global warming.

Some of these effects were noticed by those participants who travelled to Lake Nakuru (completely dry) and Lake Naivasha (water level a few meters lower than normal). The greater Horn of Africa first saw record droughts and, right during the time of the conference, heavy flooding. The snow and ice caps on Mount Kilimanjaro and Mount Kenya are predicted to disappear within a few decades, which will cause severe water shortages for the region. Setting up the climate summit in Nairobi therefore raised expectations that, first, the necessity for mitigation would receive renewed acknowledgement and, second, that industrialised countries would lend stronger support to Africa, and Southern countries in general, to help adapt to the impacts of global warming.

Although the conference in Nairobi did not develop into 'the Africa conference' as envisioned by some, it did see some progress on important issues for developing countries such as the Adaptation Fund, the Nairobi Work Programme on Impacts, Vulnerability, and Adaptation to Climate Change, and the Clean Development Mechanism (CDM). On questions regarding the future of the regime, however, it proved to be at best a confidence-building session that served to hear further views.

\section{The Post-2012 process on future commitments}

Nairobi saw the continuation of negotiations on the future of the climate regime regarding the time after the expiry of the first commitment period of the Kyoto Protocol in 2012. The Parties to the FCCC and to the Kyoto Protocol had launched two negotiating processes in Montreal in 2005. ${ }^{5}$

First, the Parties to the Kyoto Protocol had established an Ad-hoc Working Group (AWG) on further commitments for Annex I Parties pursuant to Article 3.9 KP, which stipulates that the MOP is to initiate considerations on post-2012 commitments for Annex I Parties at least seven years before the end of the first commitment period, thus in 2005 (see section II.1).

Second, Parties to the FCCC in Montreal launched a 'dialogue' under the Framework Convention on Climate Change in the hope of integrating large developing countries and the United States, who has refused to ratify Kyoto, in constructive discussions on the future of the climate regime. The 'dialogue on long-term cooperative action to address climate change by enhancing implementation of the convention' is not supposed to prejudice 'any future negotiations, commitments, process, framework or mandate under the Convention' and is rather 'an open and non-binding exchange of views $[. .$.$] and will not open to any negotiations$ leading to new commitments. ${ }^{6}$ (see section II.3)

In Nairobi, two new items relevant to the post2012 regime, namely a review of the Kyoto Protocol under its Article 9 (see section II.2) and the Russian proposal on voluntary commitments (see section II.4), were put on the agenda.

\section{Ad Hoc Working Group on Further Commitments for Annex I Parties under the Kyoto Protocol (AWG)}

Timely negotiations on post-2012 commitments are essential. Any amendment to the Kyoto Protocol will have to be ratified by at least three-fourths of the Parties in order to come into effect. ${ }^{7}$ This will probably require two to three years and thus negotiations would have to be finalised at the latest by 2009 in order to avoid a gap between the first and second commitment period.

In Nairobi, following a workshop to explore the scientific basis of further commitments, the Parties discussed several points raised by their Chair Michael Zammit Cutajar for further consideration: the work programme of the AWG, sending an encouraging message to the outside world, a longer-

\footnotetext{
5 Wittneben/Sterk/Ott/Brouns, 'The Montreal Climate Summit: Starting the Kyoto Business and Preparing for post-2012, The Kyoto Protocol's First Meeting of the Parties (MOP 1) and COP 11 of the UNFCCC', JEEPL 2006, pp. 90-100.

6 Decision 1/CP.11, Dialogue on long-term cooperative action to address climate change by enhancing implementation of the Convention, FCCC/CP/2005/5/Add.1, 30 March 2006.

7 See Articles 20, 21 Kyoto Protocol.
} 
term vision for possible aspiration for the work to achieve the principles of the Convention, and the duration of the commitment period.

After a number of informal consultations and bilateral meetings, the Parties again could not agree on a specific timeline. ${ }^{8}$ The developing countries (G77 and China) had demanded that negotiations on further commitments for Annex I Parties should be concluded by 2008 while the industrialised countries had stressed the necessity of receiving more information about important factors to be provided by not only Parties but by other organisations, including the Intergovernmental Panel on Climate Change (IPCC) and the International Energy Agency (IEA). The intentions underlying both positions are not difficult to decipher. The industrialised countries intended to put the negotiations on Articles 3.9 and 9 into one package to negotiate a 'broader participation' in the regime. This included strengthened action by the major developing countries or a condition for taking on any new and strengthened commitments under Article 3.9 KP. Developing countries wanted Annex I Parties to take the lead by determining their further commitments in the AWG first before negotiating future commitments for themselves. They therefore insisted that the negotiations on future targets for the industrialised countries and the broader review of the Protocol be kept separate.

The Parties did manage to agree on a work programme to (a) conduct an analysis of mitigation potentials and ranges of emission reduction objectives of Annex I Parties, (b) analyse possible means to achieve mitigation objectives, and (c) consider further commitments by Annex I Parties. In 2007, the AWG will focus on the first point. Its third session at the twenty-sixth meeting of the COP's subsidiary bodies (SB 26) in May 2007 will be devoted to a roundtable discussion based on submissions by Parties. These submissions should contain information and views on mitigation potentials, effective-

8 The conclusion contains the same phrase as the Montreal decision establishing the AWG, i.e. that further sessions will be scheduled with a view to completing the work of the AWG as early as possible and in time to ensure that there is no gap between the first and the second commitment periods under the

Kyoto Protocol, see Further commitments for Annex I Parties and Programme of Work, Draft Conclusions, FCCC/KP/AWG/2006/L.4 14 December 2006.

9 Ibid.

$10 \mathrm{lbid}$. ness, efficiency, and costs and benefits of current and future policies as well as measures and technologies at the disposal of Annex I Parties. The fourth session of the AWG is scheduled later this year in conjunction with the fourth session of the 'dialogue'.

With regards to the message to the outside world, while the EU and G77/China had attempted to send a clear signal of continuation to the growing emissions trading market, Japan repeated that key elements of the Kyoto Protocol must be reviewed before making any decisions on the continuation of the Kyoto mechanisms and insisted that industrial stakeholders should bear the risk of the continuation of the international carbon market. The conclusion thus only underscores the need for the energetic and timely pursuit of its work programme so as to send a clear message that Annex I parties to the Kyoto Protocol are taking the lead in the mitigation effort by taking action to maintain their overall emissions on a declining trend beyond 2012 through their domestic and international efforts, (which) will also give a clear signal to economic actors about the continuity of the international carbon market'.

As regards the long-term vision, the EU attempted to insert the objective to keep the temperature increase below $2^{\circ} \mathrm{C}$, but this was opposed by G77/China. After much controversy in the contact group, the final conclusions do not contain the target date set out originally for halving global GHG emissions, which was the year 2050. Instead, the AWG merely considered the information that, according to the scenarios of the Intergovernmental Panel on Climate Change Third Assessment Report, global emissions of carbon dioxide have to be reduced to very low levels, well below half of levels in 2000 , in order to stabilise their concentrations in the atmosphere.' ${ }^{10}$

\section{Article $9 \mathrm{KP}$ : review of the Kyoto Protocol}

Article 9 of the Kyoto Protocol prescribes a general review of the adequacy of the Protocol at regular intervals, with the first review starting at MOP 2 . The most contentious issues turned out to be the scope and duration of this first review and the institutionalisation of further reviews. G77/China argued that a review should focus on how well 
industrialised countries are meeting their targets, should be concluded at MOP 2 and that further reviews should take place at intervals of three to four years. The EU, supported by Switzerland and Japan, proposed to start a review process culminating at MOP 3 with the aim of a comprehensive assessment of all aspects of the Protocol and to conduct the second review two years after.

Finally, Article 9 was brought up to the ministerial level. The ministers agreed to conclude the first review at MOP 2. The conclusions state that the Kyoto Protocol 'has initiated important action' although some elements such as adaptation 'could be further elaborated upon' and implementation 'could be further enhanced.' ${ }^{11}$ Parties also agreed to conduct the second review at MOP 4 in 2008, as the industrialized countries had wanted, but with a mandate 'which shall not pre-judge action that may be decided upon by the COP/MOP, and shall not lead to new commitments for any Party ${ }^{12}$, as developing countries had insisted. The scope and content of the second review will be considered at MOP 3 , based on Parties' submissions by 17 August 2007.

This decision in combination with the AWG conclusions seems to close the window of opportunity to come to an agreement on future commitments for industrialised countries or on broader participation before 2008. The prevailing mood at this conference was thus one of 'passing the baton'. Having said that, the review will be comprehensive - as demanded by industrialised countries - and will encompass all aspects of the Kyoto Protocol. Together with the results of the Fourth Assessment Report of the IPCC it has thus the potential to provide the basis for a comprehensive agreement covering Annex I and nonAnnex I countries.

\section{Dialogue on long-term cooperative action to enhance implementation of the Convention}

There had been some expectation after COP 11 in Montreal that the Convention track might provide a forum for an open exchange of views and information and could be a basis for the future negotiation on broader participation. ${ }^{13}$ After a first round of submissions by Parties and a first workshop held in May 2006, Nairobi saw the second workshop of the Dialogue. Following presenta- tions by economists such as Sir Nicholas Stern, Parties exchanged their views on four themes: advancing development goals in a sustainable way, realising the full potential of market-based opportunities, addressing action on adaptation and realising the full potential of technology. Highlights included China's presentation on its domestic climate protection efforts, Brazil's proposal to assist developing countries in reducing emissions from deforestation by providing financial incentives in the form of payments from developed countries, and South Africa's proposal for developing countries to commit to Sustainable Development Policies and Measures.

Despite its innovative format, the dialogue already seems to have run out of momentum. Parties spent little energy on it, perhaps because it is not a formal negotiation process.

The third workshop has been scheduled for May 2007 in Bonn, focusing on addressing action on adaptation and realising the full potential of technology. The fourth workshop will be held between sessions, most likely in September 2007. The FCCC secretariat will prepare an analysis of existing and planned financial flows related to climate change by the fourth session. ${ }^{14}$

\section{The Russian proposal on voluntary commitments}

In Montreal, Russia had proposed to establish a procedure for recognising voluntary commitments from Non-Annex I Parties to the Protocol. Based on inter-sessional consultations, the Russian Federation called for a MOP decision to launch a negotiation process under the Subsidary Body for Implementation (SBI). Fearing a new arena for negotiations of developing country commitments, this proposal was opposed by the G77/China who stated that there was no mandate to negotiate this item at MOP 2. After much debate, the issue was taken to

\footnotetext{
11 Decision 7/CMP.2, Review of the Kyoto Protocol pursuant to its Article 9, FCCC/KP/CMP7/2006/10/Add.1, 26 January 2007 (Advance version).

12 Ibid.

13 Supra note 5, p. 93

14 Report of the Conference of the Parties on its twelfth session, held at Nairobi from 6 to 10 November 2006 FCCC/CP/2006/5, 26 January 2007.
} 
the ministerial level, which led to a compromise to convene a workshop in May 2007 to clarify and explore the scope and implications of the proposal. ${ }^{15}$

\section{Belarus proposal to take on commitments}

Belarus is an Annex I Party but was not assigned a commitment under Annex B of the Kyoto Protocol since it was not a Party to the FCCC in $1997 .{ }^{16}$ In Nairobi, Belarus proposed to take on a $5 \%$ reduction target relative to 1990 levels. The proposal, however, faced opposition from all sides for several reasons: Firstly, the scientific basis for a $5 \%$ reduction commitment for Belarus was not clear. Second, this commitment would grant 'hot air', i.e. excess emission certificates not resulting from active climate policy, to Belarus since its emissions have already fallen by about $40 \%$ below 1990 levels. ${ }^{17}$ After a number of informal consultations, Belarus accepted a target of $8 \%$ reduction with further conditions, including a requirement of holding $7 \%$ of its allowance in reserve in addition to the normal $5 \%$ reserve, and a commitment to use any proceeds from emissions trading for emission abatement measures. $^{18}$

This decision constitutes the adoption of the first amendment to the Kyoto Protocol. However, the amendment will come into effect only if it is ratified by three-fourths of the Kyoto Parties. ${ }^{19}$ Since

15 Conclusions on the report of the President on consultations concerning the proposal of the Russian Federation. Proposal by the President, FCCC/KP/CMP/2006/L.6, 17 November 2006.

16 See Oberthür/Ott, The Kyoto Protocol, International Climate Policy for the 21 st Century, Berlin, Heidelberg et al. 1999, p. 155.

17 Report of the individual review of the greenhouse gas inventory of the Republic of Belarus submitted in 2005 FCCC/ARR/2005BLR, 24 March 2006.

18 Decision 10/CMP.2, Proposal from Belarus to amend Annex B to the Kyoto Protocol, FCCC/KP/CMP7/2006/10/Add.1, 26 January 2007 (Advance version).

19 Supra note 7.

20 Supra note 5, p. 93.

21 Reducing emissions from deforestation in developing countries: approaches to stimulate action, Submissions from Parties, FCCC/CP/2005/MISC.1, 11 November 2005.

22 Decision 1/CP.10, Buenos Aires programme of work on adaptation and response measures, FCCC/CP/2004/10/Add.1, 19 April 2005; see also Ott/Brouns/Sterk/Wittneben, 'It takes two to tango: Climate Policy at COP 10 in Buenos Aires and Beyond', JEEPL 2005, pp. 84-91. the EU clearly stated that its Member States would not ratify the amendment, the decision is unlikely to actually enter into force.

\section{Deforestation}

$20-25 \%$ of global emissions result from deforestation, but so far neither the Convention nor the Protocol have adequately addressed these emissions. A joint submission by Papua New Guinea and Costa Rica at COP 11 in Montreal emphasised the need for innovative approaches in this area. ${ }^{20}$ They proposed a 'fair and equitable access to carbon markets' as a condition for substantial engagement and made two suggestions: either to elaborate an optional Protocol under the Climate Convention or to make forest conservation activities eligible under the CDM. ${ }^{21}$

In Montreal, all Parties had welcomed the general intention of the proposal, while some raised technical concerns to address deforestation emissions without creating another loophole in the climate regime, such as how to set the baselines or targets, which areas to include, or how to monitor and verify the benefits achieved. In a workshop earlier in 2006, Brazil had submitted a competing proposal according to which countries would not get emission credits for reducing deforestation but payments from an international fund financed by the industrialised countries.

In Nairobi, the G77/China and the EU were in favour of the Brazilian proposal. The US was very reluctant to negotiate, insisting that a multitude of technical questions needed to be resolved. The Parties finally agreed to hold a second workshop on this issue in early 2007. Issues to be discussed are possible positive incentives to prevent deforestation as well as technical and methodological requirements for their implementation.

\section{Adaptation}

After some initial neglect in the first years of the climate regime, adaptation to the adverse effects of climate change gained considerable momentum at COP 9 in Milan 2003, where the Parties agreed on a comprehensive approach. At COP 10 the Parties adopted the 'Buenos Aires Programme of Work on Adaptation and Response Measures'.22 It called 
on the Subsidiary Body for Scientific and Technological Advice (SBSTA) to develop a five-year programme of work on scientific, technical and socio-economic aspects of vulnerability and adaptation to climate change. This programme of work was adopted at COP 11 in Montreal. ${ }^{23}$

To achieve the aims of the programme, SBSTA 23 in Montreal had elaborated a seven-page draft indicative list of activities for information gathering, analysis and dissemination. ${ }^{24}$ While SBSTA 24 (May 2006 in Bonn) failed to completely agree on the list, Parties nevertheless decided to launch the activities under the programme and to complete the list at SBSTA 25 in Nairobi.

MOP 2 in Nairobi finally agreed on the initial activities to be undertaken in the first two years of the programme of work. The very comprehensive programme, now renamed the 'Nairobi Work Programme on Impacts, Vulnerability and Adaptation to Climate Change', includes submissions, workshops and expert meetings; deliverables include synthesis reports, technical papers, progress reports and a web-based interface.

The other key issue on the adaptation agenda in Nairobi was the establishment of the Adaptation Fund (AF), which had been agreed upon at COP 7 in Marrakesh and established at MOP 1 . It will be funded from a $2 \%$ levy on the issuance of Certified Emission Reductions under the CDM. However, the fund has so far not been operationalised due to disagreement regarding its institutional setup. The EU and other industrialised countries prefer to hand over the operation to the Global Environment Facility (GEF), the entity already in charge of operating the climate regime's Special Climate Change Fund and Least Developed Countries Fund.

According to its mandate, the GEF finances only 'agreed incremental costs' that arise if a local, national or regional development project is made to also yield global environmental benefits. Activities therefore require co-financing and in particular LDCs and Small Island Developing States (SIDS) fear that this obligation is favouring countries that already receive the bulk of foreign direct investment or Official Development Assistance (ODA) flowing to the South. Further conflicts arose from the adoption of a Resource Allocation Framework (RAF) in 2005 that earmarks funds according to an index of the potential of countries to generate global environmental benefits and an index of coun- tries' performance in implementing GEF projects. While the RAF in principle only applies to the GEF's own funding, which is distinct from the funds of the climate regime, some developing countries fear that these criteria will eventually come to apply to all GEF financing.

Furthermore, since most of the resources for the AF will probably not come from donor countries but from the CDM, developing countries question the legitimacy of the GEF, where donor governments play a dominant role, to handle this fund. Also, the substantial political power that the US can exercise in the decision-making processes at the GEF could make this body inappropriate for managing a fund that is driven by the Kyoto Protocol, which the US has not ratified.

By contrast, the EU supports the location of the fund in the GEF in order to ensure that project activities are coordinated with the other financial mechanisms of the climate regime (Least Developed Country Fund and Special Climate Change Fund) and is also in favour of the co-financing requirement.

In Nairobi, Parties agreed to first address the AF's overarching principles, modalities and governance before addressing institutional arrangements. They finally resolved that funding shall be on a full adaptation cost basis, that the Fund's governing body shall be composed only of Parties to the Kyoto Protocol, follow the 'one-country-onevote' rule, and have a majority of developing countries in the fund's decision-making body. The SBI is to further elaborate on eligibility criteria, priority areas and institutional arrangements for consideration at MOP $3 \cdot{ }^{25}$ Since the GEF is currently undergoing great restructuring, the hope is that an overall structure will emerge that will allow for a fund as defined by the guidance from Nairobi to be established to everyone's satisfaction within the GEF. The MOP has thus invited institutions to submit their views on how they would operationalise this decision. ${ }^{26}$ Another reason for the delay in setting up the fund has been because con-

\footnotetext{
23 See supra note 5, pp. 96 et seq.

24 Scientific, technical and socio-economic aspects of impacts, vulnerability and adaptation to climate change, FCCC/SBSTA/2005/L.30, 7 December 2005.

25 Decision 5/CMP.2, Adaptation Fund, FCCC/KP/CMP7/2006/10/ Add.1, 26 January 2007 (Advance version).

26 Ibid.
} 
sensus within G77/China still has to be established regarding eligibility criteria and other issues.

\section{The project-based mechanisms: Clean Development Mechanism and Joint Implementation}

\section{The Clean Development Mechanism}

The CDM allows industrialised countries to acquire Certified Emission Reductions (CERs) generated by climate protection projects in developing countries and count these towards their Kyoto targets. Especially in the year 2006, the CDM has been expanding rapidly and there are currently more than 1,500 projects at least at the validation stage, exceeding even the most optimistic estimates of the CDM Executive Board (EB). ${ }^{27}$ Parties thus acknowledged the EB's work as a great success.

However, CDM projects are so far mainly concentrated in a few countries, notably Brazil, China, India, and Mexico, which account for about 3/4 of all projects currently in the pipeline. This issue had already been raised at MOP 1 in Montreal, which had requested the EB to develop recommendations on how to improve the CDM's geographical distribution. ${ }^{28}$ Negotiations in Nairobi focused on one of the EB's suggestions, a facility or facilities to promote capacity building and project preparation in countries that have so far been left out of the CDM process. The idea was strongly supported by the group of African countries and Least Developed Countries (LDCs) but opposed by the industrialised countries who did not want yet another financial mechanism at international level. Parties finally compromised on language encouraging Annex I Parties to consider further initiatives, including financial support' for the identification and development of CDM projects especially in LDCs, African countries, and small island developing states. ${ }^{29}$

\footnotetext{
27 Fenhann, Joergen (2006): CDM pipeline overview, updated 1 February 2006: www.cd4cdm.org.

28 Supra note 5, pp. 97-99.

29 Decision 1/CMP.2, Further guidance relating to the clean development mechanism, FCCC/KP/CMP7/2006/10/Add.1, 26 January 2007 (Advance version).

30 Ibid.

31 lbid.
}

Another highly controversial issue in this context was projects that reduce the use of non-sustainable biomass, i.e. biomass that is used at a rate faster than the natural replacement rate, e.g. by increasing the efficiency of biomass use or replacing it with solar cookers. In 2005, the EB had deleted references to this project type from the small-scale methodologies, thus effectively blocking them. On the insistence of LDC countries MOP 1 had asked the EB to revisit the issue, but the Board was unable to come to an agreement and had therefore referred the problem back to the MOP. In Nairobi, MOP 2 was equally unable to resolve the issue and therefore invited Parties, intergovernmental organisations and non-governmental organisations to submit new proposals for methodologies to the EB. The EB is to make a recommendation on a new methodology to MOP $3 .{ }^{30}$

Concerning the issue of whether the carbon capture and storage (CCS) technology can be applied in a CDM project, a number of methodological, political and legal questions were raised. These include the definition of the project boundary, leakage, the permanence of the sequestration, and responsibility after the crediting period of the CDM project ends. The EU, Canada, China, India, Japan, South Africa and especially the OPEC countries clearly supported to include CCS under the CDM, but the EU amongst other countries highlighted that the above mentioned issues first needed to be resolved. Other countries such as the LDCs, the Alliance of Small Island States (AOSIS) and Brazil voiced serious concerns about the maturity and appropriateness of CCS. Parties compromised on a two-year process of further negotiations under the Subsidiary Body for Scientific and Technological Advice (SBSTA), with a view to taking a final decision at MOP $4 \cdot{ }^{31}$

The MOP also had the issue of CDM projects that reduce emissions of HFC-23 on its agenda. HFC-23 is a by-product in the production of hydrochlorofluorocarbon 22 (HCFC-22), a refrigerant governed by the Montreal Protocol on Substances that Deplete the Ozone Layer. HFC-23 incineration at existing production sites can already generate CERs, but the EB had requested guidance from the MOP on whether incineration at new facilities was also permitted under the CDM. Since HFC-23 CDM projects are quite profitable with costs of only about USD 0.50 per $\mathrm{CO}_{2}$ equivalent tonne of HFC-23 avoided, there are concerns that permitting 
such projects would create a perverse incentive to increase production of HCFC-22 for the sole purpose of generating CERs.

Negotiations focussed on a proposal to establish a system by which the CERs would be issued to an institution other than the project participants. The institution would sell a fraction of the CERs to reimburse the project participants' incremental costs incurred from destroying the HFC-23. However, while most Parties supported issuing the CERs to an international institution and either cancelling them or using them to fund activities to phase out the production and consumption of HCFCs altogether, China wanted the CERs to be issued to the host country government and to be used for 'other activities beneficial for the global environment'. The discussion therefore had to be deferred to SBSTA 26 in May 2007.

\section{Joint Implementation}

In contrast to the controversies surrounding the CDM, negotiations about Joint Implementation (JI), under which Annex I Parties can acquire emission reduction units (ERUs) generated by greenhouse gas mitigation projects in other Annex I Parties, were largely uncontroversial. MOP 1 had established the Joint Implementation Supervisory Committee (JISC) that oversees the implementation of the JI 2nd track and tasked it to make the mechanism operational within the year. ${ }^{32}$ The JISC had met this challenge and already launched the 2nd track verification procedure in October 2006. However, the future work is currently endangered by a shortfall of more than 2 million USD the JISC faces for 2007. The JI mechanism will start yielding revenues for its operation only in 2008. In the meantime it relies on funding from the Parties to the Protocol, which has so far not come forward to the extent necessary. The MOP therefore urged Parties to make further financial contributions for the operation of the JISC. ${ }^{33}$

\section{Technology transfer}

According to Article 4.5 of the UNFCCC and Article 10(c) of the Kyoto Protocol, Annex II industrialised countries are committed to promote, facilitate and finance the transfer of technology in order to speed up the diffusion of emission reduction and adaptation technology. The Marrakesh Accords have put in place a framework that is to implement activities to determine and evaluate technology needs, exchange technological information, create a favourable framework, particularly in countries with economies in transition and developing countries, build technical capacity and put in place technology transfer mechanisms. The funding for the framework derives mainly from the GEF and from the Special Climate Change Fund.

Negotiations in Nairobi focused on the future mandate of the Expert Group on Technology Transfer (EGTT), which is undertaking analytical work and whose mandate expired at this session. Developing countries strongly called for replacing it with a new and stronger body, a so-called Technology Transfer and Development Board, and to also establish a Multilateral Technology Acquisition Fund to buy intellectual property rights. These proposals were opposed by the developed countries that instead argued for continuing and strengthening the EGTT. Parties were unable to bridge this division and finally decided to extend the mandate of EGTT for one year and continue discussions at $\mathrm{SB} 26^{34}$

\section{Conclusions and ways forward}

The 2006 climate conference (COP 12 / MOP 2) in Nairobi certainly will not be remembered as a 'great' conference, but as one that largely failed to address the challenges posed by accelerating climate change. The slow progress of the climate negotiations is increasingly out of step with the

\footnotetext{
32 The JI 2nd track is essentially a fall-back mechanism for Jl host countries that do not fulfil all the eligibility criteria for participating in the flexible mechanisms established by the Marrakesh Accords. These criteria mostly relate to the existence of rigorous emission inventories. Host countries that meet all criteria qualify for the Jl 1st track under which they can define the approval process of projects themselves. Countries that meet only a reduced set of criteria can only use the JI 2nd track, which requires a more complex international approval procedure similar to the CDM overseen by the JISC.

33 Decision 2/CMP.2, Implementation of Article 6 of the Kyoto Protocol, FCCC/KP/CMP7/2006/10/Add.1, 26 January 2007 (Advance version); Decision 3/CMP.2, Guidance on the implementation of Article 6 of the Kyoto Protocol, FCCC/KP/CMP7/ 2006/10/Add.1, 26 January 2007 (Advance version).

34 Decision 5/CP.12, Development and transfer of technologies, FCCC/CP/2006/5/Add. 1, 26 January 2007 (Advance version).
} 
rising urgency of the climate problem. Despite individual consciousness of the scale of the challenge, the collective wisdom of the negotiators appeared to be at a rather low level. The AOSIS countries were particularly frustrated because even the $2^{\circ} \mathrm{C}$ target pronounced by the European Union, which was not agreed by other developed and developing countries in any case, will probably mean that many islands will be submerged by the rising oceans.

Nevertheless, the Nairobi conference did keep the Kyoto process alive. The post-2012 negotiations are continuing and will now include an analysis of mitigation potentials. The Compliance Committee successfully started its work, reported to the Parties and adopted its Rules of Procedure. Many details were accomplished that had been lingering in the negotiations and that had been kept as potential future bargaining chips.

Furthermore, if all goes well, the first climate conference in sub-Saharan Africa may have laid the groundwork for a more comprehensive SouthNorth agreement in the years to come. MOP 2 resolved some issues that are important for Southern countries, such as the Nairobi Work Programme on Impacts, Vulnerability, and Adaptation to Climate Change.

However, the European Union did not yet provide the kind of leadership role that is required if the post-Kyoto negotiations are supposed to conclude successfully. There was still much finger pointing and waiting for others to take the first step. True, developing countries were demanding a timetable for the AWG to agree on post-2012 commitments for Annex I countries while refusing to accept a timetable for the considerations in the Article 9 review process. This is inconsistent and obviously a negotiation strategy. But why did the Union have to respond with the same measure demanding a timetable for the review process while refusing a deadline for the AWG negotiations? The EU countries still have room to reduce GHG emissions, especially when they act as a bubble and capitalise on the reduction potentials in the countries with economies in transition. The EU will only be able to build a 'green coalition' with

35 See supra note 16, pp. 85-91.

36 See Ott, 'The Bonn Agreement to the Kyoto Protocol: Paving the Way for Ratification', International Environmental Agreements: Politics, Law and Economics, 1, 2001, 4, pp. 469-476. rapidly industrialising developing countries if it demonstrates that it is doing its share. Since per capita emissions in most industrialised countries are still very high, this means that industrialised countries are occupying other countries' environmental space.

At the present stage of the post-2012 negotiations a good and timely outcome is still possible. The work programme for the AWG has been adopted and contains the right agenda. The review of the Protocol starts later than expected but will eventually lead to an evaluation in 2008. This sets the stage for an adoption of the post-2012 regime in 2009 - very late because it will leave only two years for ratification by three-fourths of the Parties until 2012. But it would still be feasible, given the necessary political will.

The situation is also more favourable because the biggest player will enter the arena soon with a greatly enhanced positive attitude. Almost all analysts agree that the position of the US administration will change after the next elections. Climate change has already now become an issue where potential candidates in the presidential race compete on who has the best programmes. Whether Republican or Democrat, no future President will be allowed to continue with the hostile attitude of the present administration towards the Kyoto Protocol and target-based commitments in general.

This does not mean, however, that the US administration will be ready to commit already in 2009. The new administration will assume power in January 2009 and start the necessary research to determine the mitigation potentials and possible measures. The results may not be available by the end of 2009 when the negotiations are supposed to conclude. The 'rest of the world' thus may have to agree on a post-2012 regime without a definite commitment by the United States. It would therefore be productive to start considering what kind of signal from Washington might be sufficient to make the rest of the world comfortable with going ahead without a full US reintegration into the climate regime for the time being. And to also consider what could be ways to partly reattach the US to the regime once US domestic climate policy has been defined pending its full reintegration.

Again, as in 1997, the involvement of heads of state or government will be decisive. ${ }^{35}$ The 
same happened in 2001, when the Kyoto Protocol was rescued from the almost fatal blow it received when George W. Bush announced his 'opposition' to the Kyoto Protocol. ${ }^{36}$ The implications of fighting climate change reach very far and too many societal and economic interests are involved to allow ministers taking the final decisions. As it was expressed by Kofi Annan in his address to the Nairobi meeting: 'Global climate change must take its place alongside those threats (conflict, poverty, the proliferation of deadly weapons) that have traditionally monopolised first-order political attention. ${ }^{37}$

37 www.un.org/News/Press/docs/2006/sgsm10739.doc.htm. 


\section{Contents}

Editorial

FOCUS: NATURE AND HABITAT PROTECTION

Habitats Directive and Environmental Assessment of Plans and Projects

Agustín García Ureta

SPAs and SACs in Conversion Areas?

Gero von Daniels and Markus Appel

Liability Directive - a Useful Tool for Nature Protection?

Karl-Heinz Fehr, Barbara Friedrich and Susanne Scheil

Nature Conservation and Landscape Protection Including the Natura 2000 Network in the Czech Legal System

Vojtěch Stejskal

The Implementation of the Habitats Directive in Belgium (Flanders):

back to the Origin of Species?

Hendrik Schoukens, Peter Desmedt and An Cliquet

\section{ARTICLES}

The Nairobi Climate Change Summit (COP 12 - MOP 2):

Taking a Deep Breath before Negotiating Post-2012 Targets?

Wolfgang Sterk, Hermann E. Ott, Rie Watanabe and Bettina Wittneben

REACH - a Reality and the Future

Mark Blainey

\section{EU JURISDICTION}

Recent Case-Law of the European Court of Justice and the Court of First Instance

\section{Environmental Impact Assessment}

Implementation of a project without examination of an alternative solution

Infringement proceeding Commission v Portugal 


\section{Waste Management}

Meat-and-bone meal - exclusion from the application of Regulation No 259/93

ECJ, Judgment of 1 March 2007 - Case C-176/05

Preliminary ruling from the Landesgericht für Zivilrechtssachen Wien (Austria)

in the proceedings $K V Z$ retec $G m b H v$ Austria

Transport de débris de câble composés de différentes substances de la liste verte

Conclusions de l'Avocat Général M. P. Mengozzi présentées le 15 Février 2007 - Affaire C 250/0

Procédure préjudicielle formée par le Rechtbank te Rotterdam dans l'affaire Pubblico Ministero

contre Omni Metal Service

Treatment of waste water which escapes from a collecting system

Opinion of Advocate General Kokott delivered on 8 February 2007 - Case C-252/05

Preliminary ruling from the High Court of Justice of England and Wales in the proceedings

The Queen on the application of Thames Water Utilities Limited v The South East London Division,

Bromley Magistrates' Court

\section{Transport}

Restrictions d'exploitation liées au bruit dans les aéroports de la Communauté

Conclusions de l'Avocat Général M. P. Madurp présentées le 25 Janvier 2007 - Affaire C 422/05

Procédure d'infraction Commission contre la Belgique

\section{Miscellaneous}

Environmental tax on aggregates

ECJ, Judgment of 13 September 2006 - Case T-210/02

British Aggregates Association v Commission

\section{MISCELLANEOUS}

Editors and Country Correspondents

Imprint

Upcoming Conferences and Events

FOR $\mid$\begin{tabular}{l|l} 
J & OURNAL \\
E & UROPEAN \\
E & NVIRONMENTAL \& \\
P & LANNING \\
L & AW
\end{tabular}

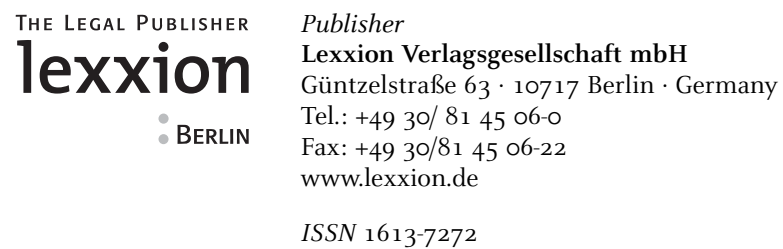

